\title{
Ngành kinh tế dẫn đầu khối KHXH\&NV về công bố quốc tế
}

Nguyễn Thanh Nhàn

17 February 2021

Báo Khoa học và Phát triển

\section{KHOA HOC.PHATTTRIÊN}

https://khoahocphattrien.vn/khoa-hoc/nganh-kinh-te-dan-dau-khoi-khxhnv-ve-cong-bo-quocte/20210129105921795p1c160.htm 


\section{Ngành kinh tế dẫn đầu khối KHXH\&NV về công bố quốc tế}

Nguyễn Thanh Nhàn (Đại học Ngoại thương) 17/02/2021 07:12

Nghiên cứu của nhóm tác giả Vương Quân Hoàng và cộng sự nhằm tìm hiểu sự thay đổi của ngành KHXH\&NV tại Việt Nam dưới góc nhìn công bố quốc tế vừa được xuất bản trên tạp chí Research Evaluation [JIF = 2.571; CiteScore $=5.6]$ do Oxford University Press ngày 17/1/2021.

Bài nghiên cứu Mirror, mirror on the wall: Is economics the fairest of them all? áp dụng thống kê Bayesian (bằng phần mềm Việt bayesvl) trên bộ dữ liệu của 1.564 nhà nghiên cứu ở bỗn lĩnh vực chính (Kinh tế, Giáo dục, Y học xã hội và Các ngành khác) có công bố quốc tế trong giai đoạn 2008-2018.

\section{Ngành kinh tế dẫn đâu}

Qua phân tích dữ liệu, nghiên cứu cho thấy: Thứ nhất, năng suất công bố quốc tế của tác giả trong ngành Kinh tế đứng đầu ở hai nhóm tuổi chính: nhóm tuổi từ 35-39 với 305 bài báo và nhóm tuổi từ 40-44 với 334 bài báo. Xét về số lượng tác giả và nhóm tác giả mới, ngành Kinh tễ đang chiếm ưu thế so với các ngành còn lại. Số lượng tác giả mới đã tăng từ trung bình 30 tác giả/năm trong giai đoạn 2008-2014 lên trung bình khoảng 100 tác giả/năm. Cuối cùng, nhóm ngành Kinh tế cũng vượt qua các nhóm ngành khác về hợp tác quốc tế, với 860 bài báo là kết quả của sự hợp tác với 62 quốc gia khác.

\section{Chênh lệch giới tính trong nghiên cứu}

Rất nhiều học giả trước đó đã đề cập tới việc mất cân bằng giới tính trong khoa học và phụ nữ được cho là yếu thế hơn nam giới. Theo nghiên cứu này, trong lĩnh vực Kinh tế và Các ngành khác, các tác giả nam đông hơn hẳn các tác giả nữ - lần 
lượt là 388 nam/245 nữ và 397 nam/281 nữ. Trong khi đó, đối với lĩnh vực Y học xã hội, số nam nữ khá cân bằng (169/179). Riêng trong ngành Giáo dục, nữ vượt trội so với nam - 129 nữ/98 nam. Cũng trong lĩnh vực Giáo dục, năng suất của các tác giả nữ tốt hơn các tác giả nam (238 bài so với 142 bài).

Bên cạnh đó, độ tuổi trung bình của các nhà nghiên cứu nam ( 41 tuổi) cao hơn các nhà nghiên cứu nữ ( 36 tuổi) trong mọi lĩnh vực. Điều này cho thấy lực lượng các tác giả trẻ (giai đoạn vừa hoàn thành tiến sỹ) có sự đóng góp lớn của các nhà nghiên cứu nữ. Trong khi đó, phần đông các tác giả nam đang ở độ tuổi chín của sự nghiệp.

Tại Việt Nam, số liệu ghi nhận cho thấy số lượng nhà khoa học nữ ngày càng tăng. Trong năm 2014, tỷ lệ nhà khoa học nữ có bằng Thạc sĩ chiếm $43 \%$ và có bằng Tiến sĩ chiếm 21\%; còn trong giai đoạn 2012-16, tỷ lệ nhà khoa học nữ trở thành giáo sư và phó giáo sư là $24,6 \%$. Thúc đẩy sự nghiệp của các nhà nghiên cứu nữ cũng là một cách hiệu quả để tăng khả năng cạnh tranh và mở rộng ranh giới của khoa học nước nhà

\section{Đáp ứng tiêu chuẩn quốc tế}

So với Giáo dục và Y học xã hội, Kinh tế và các lĩnh vực khác có số lượng đối tác quốc tế cao hơn đáng kể với lần lượt là 62 và 56 quốc gia. Trong khi đó, mạng lưới hợp tác trong Giáo dục và Y học xã hội còn hẹp, chỉ với 28 và 40 quốc gia. Úc và Bắc Mỹ là hai đối tác hợp tác chính trong các lĩnh vực, điều này cho thấy xu hướng hợp tác với các nước phát triển phương Tây trong cộng đồng khoa học Việt Nam.

Áp lực công bố có thể coi là một trong các nguyên nhân dẫn đến sự gia tăng trong hợp tác quốc tế. Hiện nay, việc phát triển Internet và áp lực phải công bố bài một cách nhanh chóng đòi hỏi các tác giả Việt Nam cân có sự chuẩn bị cho nhiều hoạt động hợp tác quốc tế hơn.

\section{Nguyễn Thanh Nhàn (Đại học Ngoại thương)}




\section{Tài liệu tham khảo:}

[1] Vuong, Q. H., et al. (2021). Mirror, mirror on the wall: Is economics the fairest of them all? An investigation into the social sciences and humanities in Vietnam. Research Evaluation, 30. DOI:10.1093/reseval/rvaa036.

[2] La, V. P., \& Vuong, Q. H. (2019). bayesvl: Visually learning the graphical structure of Bayesian networks and performing MCMC with 'Stan'. The Comprehensive R Archive Network (CRAN). Available from: https://cran.r-project.org/package=bayesvl 